\title{
Comparative seed morphology of the tribe Alsineae (Caryophyllaceae) in Korea and its taxonomic implications
}

\author{
Jun-Ho Song, Ju-Mi Kim, Min-Kyoung Ok and Suk-Pyo Hong*
}

Laboratory of Plant Systematics, Department of Biology, Kyung Hee University, Seoul, 02447, Korea

(Received 5 October 2015; Revised 6 November 2015; Accepted 9 December 2015)

\section{한국산 Alsineae (석죽과) 종자의 형태비교 및 분류학적 유용성}

\author{
송준호 · 김주미 · 옥민경 · 홍석표* \\ 경희대학교 이과대학 생물학과
}

\begin{abstract}
The seed morphology of 25 taxa (8 genera) of Alsineae (Alsinoideae, Caryophyllaceae) in Korea was examined using stereo (SM) and scanning electron microscopy (SEM) in order to evaluate their diagnostic values and taxonomic implications. Circular, comma-shaped, ellipsoid, ovate, pyriform, reniform, and sub-circular seed shapes were identified. The seeds of the examined taxa range from 0.28 to $4.10 \mathrm{~mm}$ in length and from 0.33 to $3.10 \mathrm{~mm}$ in width; the smallest one was found in Sagina japonica, while the largest was in Honkenya peploides var. major. A hilar appendage was found in Cerastium, Honkenya, Moehringia, and strophioles were only observed in the genus Moehringia. Based on the examination of epidermal cells of the seed surface, four micromorphological types can be distinguished, viz., the colliculate-papillate (Col-Pap), colliculate-columellate (Col-Cll), colliculate-simple (Col-Sim), and smooth ( $\mathrm{Sm}$ ) types. Descriptions of the testa shape, margin, and the degree of elevation of the anticlinal cell walls, and the outer periclinal cell walls are summarized for the tribe. Taxonomic implications of the seed micromorphological characters were also discussed, in comparison with an earlier taxonomic system.
\end{abstract}

Keywords: Caryophyllaceae, Alsineae, SEM, Seed morphology, Strophiole, Testa cell

적 요: 한국산 Alsineae (Alsinoideae, 석죽과) 8속 25분류군 종자의 형태학적 형질에 대한 식별형질로서의 가치와 분류학적 의미를 평가하기 위해 해부현미경 $(\mathrm{SM})$ 과 주사전자현미경(SEM)을 통해 관찰하고 자세히 기재하였다. 종자의 외형은 원형, 쉼표형, 타원형, 난형, 양배형, 신장형, 아원형으로 다양하게 나타났으며, 크 기는 길이 0.28-4.10 mm, 너비 0.33-3.10 mm로 개미자리(Sagina japonica)가 가장 작게 나타났고, 갯별꽃 (Honkenya peploides var. major)이 가장 크게 나타났다. 점나도나물속(Cerastium), 갯별꽃속(Honkenya), 개벼 룩속(Moehringia)에서 제 부위에 부속지가 관찰되었고, 개벼룩속(Moehringia)에서만 strophiole이 관찰되어 구 별되었다. 종자표면무늬에 따라 4가지 유형, 구릉상-유두형, 구릉상-기둥형, 구릉상-단순형, 평활상으로 구별 하였으며, 종피세포의 형태, 주변부, 수층벽 높이의 정도, 병층세포벽의 형태 등의 형질을 기재하였다. 또한, 이전에 제시된 분류체계와의 비교를 통해 종자 미세형태학적 형질의 분류학적 유용성에 대해 논의하였다.

주요어: 석죽과, Alsineae, 주사전자현미경, 종자형태, Strophiole, 종피세포

\footnotetext{
*Author for correspondence: sphong@khu.ac.kr
}

http://www.pltaxa.or.kr

Copyright (C) 2015 the Korean Society of Plant Taxonomists 
석죽과(Caryophyllaceae Juss.)는 전세계적으로 약 86속 2200 여종이 분포하며, 주로 북반구 온대지역에 서식하는 것으로 알려져 있으며(Bittrich, 1993), 탁엽, 꽃잎, 꽃받침, 열매의 형질을 기반으로 Alsinoideae Fenzl, Caryophylloideae (Juss.) Rabeler \& Bittrich, 및 Paronychioideae Meisn. 등 세 개 의 아과로 구분하여 인식되고 있다(Pax and Hoffman, 1934; Chrtek and Slavikova, 1987; Bittrich, 1993). 하지만, 최근 수 행된 분자계통학적 연구에서는 전통적으로 인식되어 온 이들 아과가 각각 단계통군을 이루고 있지 않은 것으로 나 타났고(Smissen et al., 2003; Fior et al., 2006; Frajman et al., 2009; Harbaugh et al., 2010), Greenberg and Donoghue (2011) 는 Alsinoideae, Caryophylloideae 및 일부 Paronychioideae를 분리하여 새로운 과인 Plurcaryophyllaceae A.K. Greenberg \& M.J. Donoghue로 제시 한 바 있다.

전통적인 견해에 따르면 Alsineae DC.은 Alsinoideae에 속하며, 악편상생웅예(episepalous), 밀선의 분포 등의 특징 으로 다른 족과 구별되며(Bittrich, 1993), 크게 벼룩이자리속 (Arenaria) 그룹, 별꽃속(Stellaria)-점나도나물속(Cerastium) 그룹, 개미자리속(Sagina) group 등 3 개의 그룹으로 나누어 인식된다(McNeill, 1962). 하지만, 최근의 연구에서는 $\mathrm{Pax}$ and Hoffman (1934) 및 Bittrich (1993)에 의해 제시되었던 아과 분류체계가 단계통(monophyly)이 아닌 다계통 (polyphyly)임을 들어 분자계통학적 결과를 기반으로 한 11 개의 족 분류체계를 제시하였으며, 아과 분류체계에서 과거 Alsineae에 포함되었던 분류군을 Alsineae, Arenarieae, Sagineae, Sclerantheae, Sperguleae 등 다수의 족으로 재구성 하여 인식하고 있다(Harbaugh et al., 2010).

국내에는 Alsineae (sensu Bittrich, 1993)의 전체 23개 속 중, 벼룩이자리속(Arenaria L.), 점나도나물속 (Cerastium L.), 갯 별꽃속(Honkenya Ehrh.), 나도개미자리속(Minuartia L.), 개 벼룩속(Moehringia L.), 개별꽃속(Pseudostellaria Pax), 개미 자리속(Sagina L.), 별꽃속(Stellaria L.) 총 8개 속 31종이 분 포하는 것으로 알려져 있다(Hong and Choi, 2007).

종자의 외부형태, 모양, 크기, 색깔 등은 분류학적 진단 형질로 매우 유용하다고 알려져 있으며(Heywood, 1969; Barthlott, 1984), 주사전자현미경(SEM)을 이용한 종자 표면 의 미세형태학적 형질은 석죽과 내에서 속간, 속내 뿐 아니 라 종하 분류군 등 다양한 계급 내에서 연구되어, 분류학적, 계통학적 유용성이 검증된 바 있다(Wyatt, 1984; Yildiz and Cirpici, 1998; Hong et al., 1999; Abuhadra, 2000; Yildiz, 2002; Amini et al., 2011; Kanwal et al., 2012). 특히, Alsineae (sensu Bittrich, 1993) 내에 속하는 분류군에 대한 연구는 개미자리 속(Sagina) (Crow, 1979), 개벼룩속(Moehringia) (Minuto et al., 2006), 별꽃속(Stellaria) (Mahdavi et al., 2012), 나도개미자리 속(Minuartia) (Mostafavi et al., 2013), 벼룩이자리속 (Arenaria) (Sadeghian et al., 2014)으로 최근까지도 다양한 분류군에서 이루어지고 있다.

하지만, 대부분의 연구는 속 수준 및 근연 분류군에 국
한되어 이루어졌으며(Crow, 1979; Minuto et al., 2006; Mahdavi et al., 2012; Mostafavi et al., 2013; Sadeghian et al., 2014), 족 수준에서 종자의 형태학적 형질과 분류학적 논 의는 아직까지 미비하다. 특히, 한국산 석죽과 종자형태 의 다양성과 종피세포의 미세형태학적 형질 및 분류학적 유용성에 대한 연구 또한 부족한 실정이다. 따라서, 본 연 구는 한국산 석죽과 전체의 종자형태학적 형질 연구의 일 환으로, Alsineae (sensu Bittrich, 1993)에 속하는 총 23개 속 중 국내에 분포하는 8 개 속 분류군에 대한 자세한 형질 관 찰과 기재에 목적이 있다. 또한, 식별형질로서의 가치 확 인뿐 아니라, McNeill (1962), Harbaugh et al. (2010) 등에 의 해 제시된 분류체계와 종자형질의 비교를 통해 분류학적, 계통학적 유용성을 확인하는 데 목적이 있다.

\section{재료 및 방법}

본 연구를 위한 한국산 Alsineae 시료는 벼룩이자리속 (Arenaria) 2종, 점나도나물속(Cerastium) 3종 2변종, 갯별꽃 속(Honkenya) 1종, 나도개미자리속(Minuartia) 1종 2변종, 개벼룩속(Moehringia) 1종, 개별꽃속(Pseudostellaria) 5종, 개미자리속(Sagina) 2종, 별꽃속(Stellaria) 5 종 1변종 등 총 8 속 25 분류군을 대상으로 국내 - 외 주요 표본 표본관 $(\mathrm{KH}$, KHUS, S, SKK, SUNA, UPS; abbreviations according to Thiers, 2015)으로부터 대여한 표본 또는 직접 야외에서 채집하여 경희대학교 식물표본관(KHUS)에 보관한 표본을 사용하 였다. 특히, 함경도 일대 등 북한 지역에 분포하여 시료 확 보가 어려운 벼룩이울타리(Arenaria juncea), 갯별꽃속 (Honkenya), 나도개미자리속(Minuartia) 분류군의 경우, 국 외 표본관(S, UPS)에 소장된 동일 분류군의 표본을 대여하 여 연구에 사용하였다(Appendix). 종자의 외부형태학적 형 질과 크기는 해부현미경(Stereomicroscope; SM, SZ-STU1, Olympus, Tokyo)을 이용하여 관찰하고 측정하였다. 완전 건조된 종자 시료를 알루미늄 스터브(aluminum stub) 위에 올린 다음 이온 증착기(Ion-Sputter, JFC-1100, JEOL, Tokyo) 를 이용하여 백금 $(\mathrm{Pt})$ 으로 3 분간 이온증착(Ion-coating)을 한 후, 주사전자현미경(Scanning Electron Microscope; SEM, JSM-5200, JEOL, Tokyo)을 이용하여 관찰하였다.

본 연구는 한국산 Alsineae에 한정된 연구로 가장 일반 적으로 인식되고 있는 석죽과 분류체계인 Bittrich (1993) 의 체계를 따랐고, 연구된 분류군의 학명과 국명은 Hong and Choi (2007)와 Chang et al. (2014)를 따랐다. 종자 표면 의 미세형태학적 형질에 관한 용어는 Murley (1951), Barthlott (1981), Sadeghian et al. (2014)을 참고하였다.

\section{결 과}

한국산 Alsineae에 포함되는 8속 25분류군 종자의 형태 학적, 미세형태학적 형질을 관찰하고 기재하였다. 종자의 
외형, 크기, 색, 부속지 유무, 종자의 표면무늬, 종피세포 형태 등의 형질기재는 Table 1에 제시하였다.

\section{한국산 Alsineae 분류군 종자의 외부형태학적 형질:} 외형, 크기, 색, 부속지 유무

한국산 Alsineae 종자의 외형은 다양하게 나타났는데, 원형(C, circular; e.g., Fig. 2K), 쉼표형(Co, comma-shaped; e.g., Fig. 1M), 타원형(E, ellipsoid; e.g., Fig. 2I), 난형(O, ovate; e.g., Fig. 2E), 양배형(P, pyriform; e.g., Fig. 1A), 신장형(R, reniform; e.g., Fig. 1Q), 아원형(SC, sub-circular; e.g., Fig. 1S) 으로 확인되었다. 연구된 분류군의 종자의 크기는 길이가 $0.28 \mathrm{~mm}$ [개미자리(Sagina japonica)]에서 $4.10 \mathrm{~mm}$ [갯별꽃 (Honkenya peploides var. major)]으로 나타났고, 너비가 0.33 $\mathrm{mm}$ [큰개미자리(Sagina maxima)]에서 $3.10 \mathrm{~mm}$ [갯별꽃(H. peploides var. major)]으로 확인되었다(Table 1). 종자의 색은 갈색(brown), 진갈색(dark brown), 적갈색(red brown), 황갈 색(yellow brown)으로 다양하게 나타났고, 광택의 유무 (dull/shiny)에 따라 구별되었는데, 갯별꽃(H. peploides var. major)의 광택이 가장 강하게 나타났다. 부속지(appendage) 는 연구된 분류군 내에서 일부 속에서만 확인되었는데, 점 나도나물속(Cerastium) 내 모든 분류군에서 제(hilum) 부위 에 나선형의 부속지가 관찰되었고(Fig. $1 \mathrm{E}, 1 \mathrm{G}-\mathrm{I})$, 갯별꽃 속(Honkenya)의 갯별꽃(H. peploides var. major)에서는 제 부 위에 곤봉형의 부속지가 확인되었다(Fig. $1 \mathrm{~K}$ ). 특히, 개벼 룩속(Moehringia)의 개벼룩(M. lateriflora)은 strophiole이 나 타나 다른 분류군과 구별되었는데, strophiole 안쪽 제 부위 에 곤봉형의 부속지가 확인되었다(Fig. 1S).

\section{한국산 Alsineae 분류군 종자의 미세형태학적 형질: 표면무늬, 종피세포 형태 \\ 종자의 표면무늬는 종피세포의 형태에 따라 크게 구릉 상 $(\mathrm{Col}$, colliculate), 평활상 $(\mathrm{Sm}, \mathrm{smooth})$ 으로 구분하였다.}
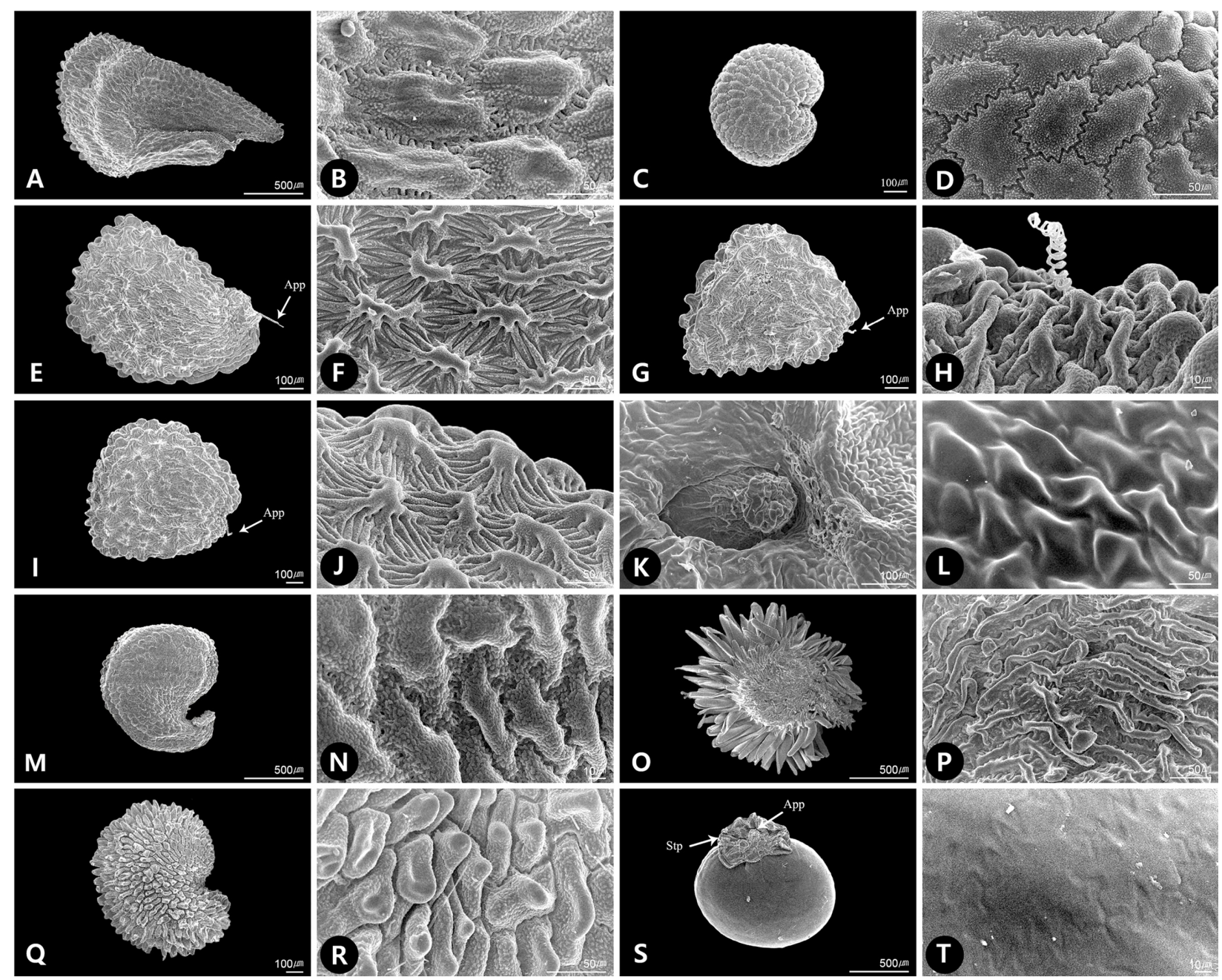

Fig. 1. SEM micrographs of seed morphology of Alsineae in Korea. A, B. Arenaria juncea; C, D. Arenaria serpyllifolia; E, F. Cerastium fischerianum; G, H. Cerastium pauciflorum; I, J. Cerastium rubescens; K, L. Honkenya peploides var. major; M, N. Minuartia arctica; O, P. Minuartia macrocarpa var. koreana; Q, R. Minuartia verna var. coreana; S, T. Moehringia lateriflora. App, appendage; Stp, strophiole. 
Table 1. Details of seed morphological characteristics in selected taxa of the tribe Alsineae in Korea. Bittrich (1993)'s generic classification is applied and taxa names follows Hong and Choi (2007). Abbreviations: Shape: C, circular; Co, comma-shaped; E, ellipsoid; O, ovate; P, pyriform; R, reniform; SC, sub-circular. Color: $\mathrm{Br} / \mathrm{D}$, brown and dull; $\mathrm{Br} / \mathrm{S}$, brown and shiny; $\mathrm{DBr} / \mathrm{D}$, dark brown and dull; $\mathrm{DBr} / \mathrm{S}$, dark brown and shiny; $\mathrm{RBr} / \mathrm{D}$, red brown and dull; $\mathrm{RBr} / \mathrm{S}$, red brown and shiny; $\mathrm{YBr} / \mathrm{S}$, yellow brown and shiny. App, appendage. Sculpture: Col-Cll, colliculatecolumellate; Col-Pap, colliculate-papillate; Col-Sim, colliculate-simple; Sm, smooth. +, present; -, absent.

\begin{tabular}{|c|c|c|c|c|c|c|c|c|c|c|}
\hline \multirow[b]{2}{*}{ Taxon } & \multirow[b]{2}{*}{ Shape } & \multirow[b]{2}{*}{$\begin{array}{l}\text { Length } \\
(\mathrm{mm})\end{array}$} & \multirow[b]{2}{*}{$\begin{array}{l}\text { Width } \\
(\mathrm{mm})\end{array}$} & \multirow[b]{2}{*}{ Color } & \multirow[b]{2}{*}{ App } & \multirow[b]{2}{*}{ Sculpture } & \multicolumn{4}{|c|}{ Testa cell } \\
\hline & & & & & & & Shape & Margin & $\begin{array}{l}\text { Anticlinal } \\
\text { wall }\end{array}$ & Outer periclinal wall \\
\hline \multicolumn{11}{|l|}{ Arenaria } \\
\hline A. juncea & $P$ & $0.88(0.98) 1.08$ & $0.50(0.56) 0.65$ & $\mathrm{Br} / \mathrm{D}$ & - & Col-Sim & $\begin{array}{l}\text { Elongated } \\
\text { polygonal }\end{array}$ & Dentate & Deep & Convex \\
\hline A. serpyllifolia & $\mathrm{R}$ & $0.45(0.46) 0.50$ & $0.53(0.54) 0.56$ & $\mathrm{DBr} / \mathrm{D}$ & - & Col-Sim & Polygonal & Dentate & Deep & Slightly convex \\
\hline \multicolumn{11}{|l|}{ Cerastium } \\
\hline C. fischerianum & $\mathrm{P}$ & $0.58(0.78) 0.90$ & $0.45(0.64) 0.78$ & $\mathrm{Br} / \mathrm{S}$ & + & Col-Cll & Polygonal & Serrate & Deep & $\begin{array}{c}\text { Convex, with conical } \\
\text { elevations }\end{array}$ \\
\hline C. glomeratum & $P$ & $0.75(0.79) 0.85$ & $0.63(0.75) 0.83$ & $\mathrm{Br} / \mathrm{S}$ & + & Col-Cll & Polygonal & Serrate & Deep & $\begin{array}{c}\text { Convex, with conical } \\
\text { elevations }\end{array}$ \\
\hline C. holosteoides var. hallaisanense & $\mathrm{P}$ & $0.63(0.69) 0.70$ & $0.60(0.64) 0.70$ & $\mathrm{DBr} / \mathrm{S}$ & + & Col-Cll & Polygonal & Serrate & Deep & $\begin{array}{c}\text { Convex, with conical } \\
\text { elevations }\end{array}$ \\
\hline C. rubescens var. koreanum & $\mathrm{P}$ & $0.78(0.84) 0.90$ & $0.60(0.74) 0.83$ & $\mathrm{Br} / \mathrm{S}$ & + & Col-Cll & Polygonal & Serrate & Deep & $\begin{array}{c}\text { Convex, with conical } \\
\text { elevations }\end{array}$ \\
\hline \multicolumn{11}{|l|}{ Honkenya } \\
\hline H. peploides var. major & $\mathrm{P}$ & $3.40(3.85) 4.10$ & $2.05(2.96) 3.10$ & $\mathrm{RBr} / \mathrm{S}$ & + & $\mathrm{Sm}$ & $\begin{array}{l}\text { Irregular } \\
\text { polygonal }\end{array}$ & Straight & Shallow & Convex \\
\hline \multicolumn{11}{|l|}{ Minuartia } \\
\hline M. arctica & Co & $0.75(0.86) 1.00$ & $0.88(0.99) 1.10$ & $\mathrm{Br} / \mathrm{D}$ & - & Col-Sim & Polygonal & Dentate & Deep & Convex \\
\hline M. macrocarpa var. koreana & $\mathrm{C}$ & $1.25(1.51) 1.85$ & $1.35(1.58) 1.90$ & $\mathrm{DBr} / \mathrm{D}$ & - & Col-Sim & $\begin{array}{l}\text { Elongated } \\
\text { polygonal }\end{array}$ & Dentate & Deep & Convex \\
\hline M. verna var. coreana & $\mathrm{R}$ & $0.65(0.70) 0.73$ & $0.73(0.77) 0.80$ & $\mathrm{Br} / \mathrm{D}$ & - & Col-Cll & Polygonal & Dentate & Deep & $\begin{array}{c}\text { Convex, with conical } \\
\text { elevations }\end{array}$ \\
\hline
\end{tabular}


Table 1. Continued.

\begin{tabular}{|c|c|c|c|c|c|c|c|c|c|c|}
\hline \multirow[b]{2}{*}{ Taxon } & \multirow[b]{2}{*}{ Shape } & \multirow{2}{*}{$\begin{array}{l}\text { Length } \\
(\mathrm{mm})\end{array}$} & \multirow{2}{*}{$\begin{array}{l}\text { Width } \\
(\mathrm{mm})\end{array}$} & \multirow[b]{2}{*}{ Color } & \multirow[b]{2}{*}{ App } & \multirow[b]{2}{*}{ Sculpture } & \multicolumn{4}{|c|}{ Testa cell } \\
\hline & & & & & & & Shape & Margin & $\begin{array}{l}\text { Anticlinal } \\
\text { wall }\end{array}$ & Outer periclinal wall \\
\hline \multicolumn{11}{|l|}{ Moehringia } \\
\hline M. lateriflora & $\mathrm{SC}$ & $0.85(1.16) 1.25$ & $1.00(1.17) 1.45$ & $\mathrm{RBr} / \mathrm{S}$ & + & $\mathrm{Sm}$ & Polygonal & Ù-undulate & Indistinct & Flat \\
\hline \multicolumn{11}{|l|}{ Pseudostellaria } \\
\hline P. davidii & $\mathrm{SC}$ & $0.90(0.98) 1.05$ & $0.83(0.90) 0.98$ & $\mathrm{YBr} / \mathrm{S}$ & - & Col-Cll & Polygonal & Dentate & Deep & $\begin{array}{c}\text { Convex, with conical } \\
\text { elevations }\end{array}$ \\
\hline P. heterophylla & $\mathrm{SC}$ & $1.30(1.39) 1.65$ & $1.56(1.65) 1.75$ & $\mathrm{Br} / \mathrm{D}$ & - & Col-Cll & Polygonal & Dentate & Deep & $\begin{array}{c}\text { Convex, with conical } \\
\text { elevations }\end{array}$ \\
\hline P. okamotoi & $\mathrm{SC}$ & $1.65(1.73) 2.10$ & $1.50(1.53) 2.00$ & $\mathrm{Br} / \mathrm{D}$ & - & Col-Cll & Polygonal & Dentate & Deep & $\begin{array}{c}\text { Convex, with conical } \\
\text { elevations }\end{array}$ \\
\hline P. palibiniana & $\mathrm{O}$ & $1.45(1.75) 1.90$ & $1.20(1.41) 1.75$ & $\mathrm{RBr} / \mathrm{D}$ & - & Col-Cll & Polygonal & Dentate & Deep & $\begin{array}{c}\text { Convex, with conical } \\
\text { elevations }\end{array}$ \\
\hline P. sylvatica & $\mathrm{R}$ & $1.15(1.29) 1.38$ & $1.53(1.64) 1.75$ & $\mathrm{DBr} / \mathrm{D}$ & - & Col-Cll & Polygonal & Dentate & Deep & $\begin{array}{c}\text { Convex, with conical } \\
\text { elevations }\end{array}$ \\
\hline \multicolumn{11}{|l|}{ Sagina } \\
\hline S. japonica & E & $0.28(0.29) 0.33$ & $0.35(0.37) 0.38$ & $\mathrm{DBr} / \mathrm{S}$ & - & Col-Pap & Polygonal & Dentate & Shallow & $\begin{array}{l}\text { Convex, with central } \\
\text { stalked papillae }\end{array}$ \\
\hline S. maxima & $\mathrm{E}$ & $0.30(0.38) 0.40$ & $0.33(0.47) 0.50$ & $\mathrm{Br} / \mathrm{S}$ & - & Col-Pap & Polygonal & Dentate & Deep & $\begin{array}{l}\text { Convex, with central } \\
\text { stalked papillae }\end{array}$ \\
\hline \multicolumn{11}{|l|}{ Stellaria } \\
\hline S. alsine var. undulata & $\mathrm{C}$ & $0.50(0.56) 0.60$ & $0.45(0.52) 0.60$ & $\mathrm{DBr} / \mathrm{S}$ & - & Col-Cll & Polygonal & Dentate & Deep & $\begin{array}{c}\text { Convex, with conical } \\
\text { elevations }\end{array}$ \\
\hline S. aquatica & $\mathrm{SC}$ & $0.85(0.91) 1.00$ & $0.75(0.87) 0.95$ & $\mathrm{Br} / \mathrm{D}$ & - & Col-Cll & Polygonal & Dentate & Deep & $\begin{array}{c}\text { Convex, with conical } \\
\text { elevations }\end{array}$ \\
\hline S. filicaulis & $\mathrm{P}$ & $0.68(0.72) 0.80$ & $0.50(0.52) 0.58$ & $\mathrm{RBr} / \mathrm{S}$ & - & Col-Sim & $\begin{array}{l}\text { Elongated } \\
\text { polygonal }\end{array}$ & Dentate & Deep & Convex \\
\hline S. longifolia & $\mathrm{P}$ & $0.80(0.92) 0.95$ & $0.70(0.74) 0.98$ & $\mathrm{DBr} / \mathrm{S}$ & - & Col-Sim & Polygonal & Dentate & Deep & Convex \\
\hline S. media & $\mathrm{R}$ & $0.98(1.16) 1.17$ & $1.03(1.18) 1.38$ & $\mathrm{Br} / \mathrm{D}$ & - & Col-Cll & Polygonal & Dentate & Deep & $\begin{array}{c}\text { Convex, with conical } \\
\text { elevations }\end{array}$ \\
\hline S. radians & $\mathrm{R}$ & $1.10(1.29) 1.45$ & $0.95(1.42) 1.65$ & $\mathrm{RBr} / \mathrm{S}$ & - & Col-Sim & Polygonal & Straight & Deep & Concave \\
\hline
\end{tabular}



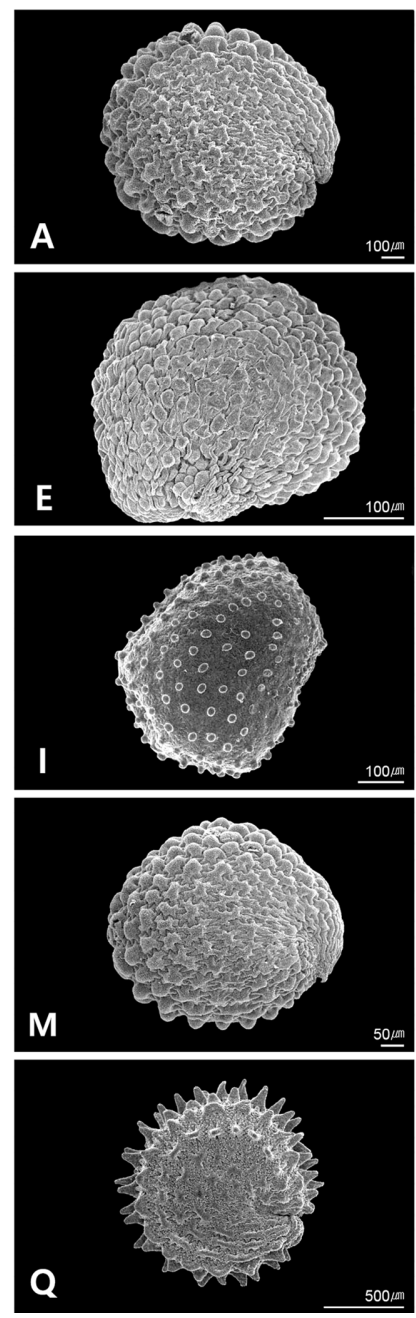

som
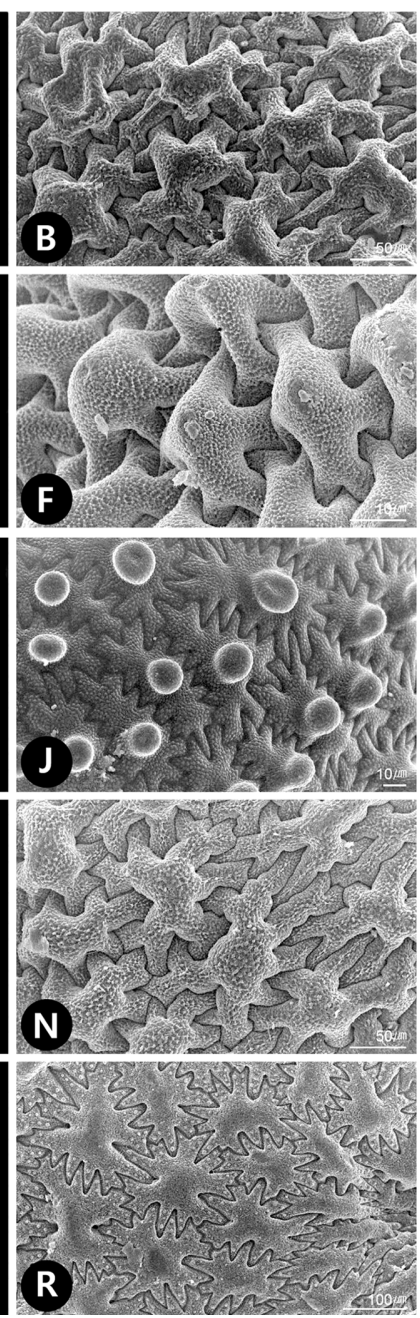
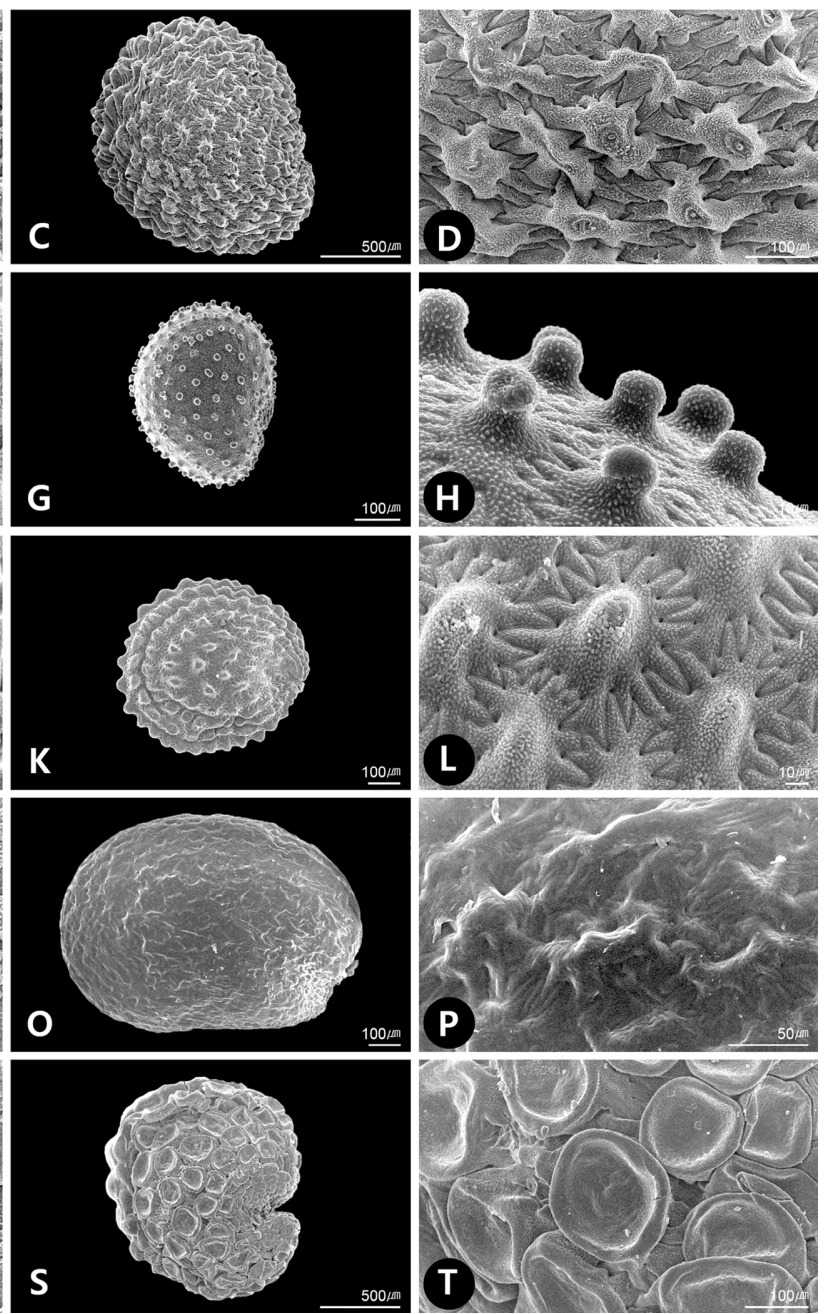

Fig. 2. SEM micrographs of seed morphology of Alsineae in Korea. A, B. Pseudostellaria davidii; C, D. P. heterophylla; E, F. P. palibiniana; G, H. Sagina japonica; I, J. Sagina maxima; K, L. Stellaria alsine var. undulata; M, N. Stellaria aquatica; O, P. Stellaria longifolia; Q, R. Stellaria media; S, T. Stellaria radians.

또한, 구릉상 $(\mathrm{Col})$ 은 병층벽(outer periclinal wall)의 형태에 따라 구릉상-유두형(Col-Pap, colliculate-papillate), 구릉상기둥형(Col-Cll, colliculate-columellate), 구릉상-단순형 (Col-Sim, colliculate-simple)의 세 유형으로 구별하였고, 연 구된 분류군 중 구릉상-기둥형(Col-Cll)이 가장 일반적인 형태로 확인되었다(Table 1). 종피세포의 형태로는 신장된 다각형(elongated polygonal; e.g., Fig. 1B), 다각형 (polygonal; e.g., Fig. 2R)이 나타났고, 세포의 주변부(margin)는 직선상 (straight; e.g., Fig. 1L), 거치상(serrate; e.g., Fig. 1F), 치아상 (dentate; e.g., Fig. 1D), $\Omega$-물결상 $(\Omega$-undulate; e.g., Fig. 1T)응 로 관찰되었다. 종피세포의 수층벽(anticlinal wall)은 돌출 (relief)여부에 따라 깊게(deep; e.g., Fig. 1D) 혹은 얕게 (shallow; e.g., Fig. 1L) 파이거나, 뚜렷하게 구별되지 않고 희미한 형태(indistinct; e.g., Fig. 1T)로 관찰되었다.

구릉상-유두형(Col-Pap)은 개미자리속(Sagina)에서만 확 인되었는데, 병층세포가 볼록(convex)하고 중앙에 유두상 세포(papillae)가 나타났다(Fig. 2G-J). 구릉상-기둥형(Col$\mathrm{Cll}$ )은 점나도나물속(Cerastium; Fig. 1E-J), 개별꽃속 (Pseudostellaria; Fig. 2A-F) 내 연구된 모든 분류군과 나도 개미자리속(Minuartia; e.g., M. verna var. coreana), 별꽃속 (Stellaria) 내 일부 분류군(e.g., S. alsine var. undulata, Fig. $2 \mathrm{~K}-\mathrm{L} ;$ S. aquatica, Fig. 2M-N; S. media, Fig. 2Q-R)에서 관 찰되었는데, 본 타입에서는 병층세포가 원뿔형(conical)으 로 볼록하게 나타나는 형태로 연구 분류군 내에서 일반적 인 형태로 확인되었다. 구릉상-단순형(Col-Sim)은 벼룩이 자리속(Arenaria; Fig. 1A-D), 나도개미자리속(e.g., $M$. arctica, Figs. 1M-N; M. macrocarpa var. koreana, Fig. 1OP), 별꽃속(Stellaria; S. filicaulis, S. longifolia, Fig. 2O-P)의 일부 분류군에서 확인되었는데, 병층세포벽이 단순히 볼 록하게 나타나는 형태를 보인다. 다만, 왕별꽃(Stellaria radians)에서만 직선형의 수층벽과 오목한 형태의 병층벽 구조가 나타나 구별되었다(Fig. $2 \mathrm{~S}-\mathrm{T}$ ). 평활상(Sm)은 갯별 
꽃속(Honkenya)과 개벼룩속(Moehringia) 내 분류군에서 확인되었는데, 갯별꽃 $(H$. peploides var. major)의 경우 종피 세포는 불규칙적인 다각형과 직선형의 수층벽, 볼록한 병 층벽을 나타냈고(Fig. $1 \mathrm{~K}-\mathrm{L}$ ), 개벼룩(M. lateriflora)은 $\Omega$-물 결상으로 뚜렷하게 구별되지 않고 희미한 형태의 수층벽 과 편 평평(flat)한 형태의 병층벽을 나타냈다(Fig. 1S-T).

\section{고 찰}

한국산 Alsineae에 포함되는 8 속 25 분류군의 종자에 대 하여 다양한 형태학적(외형, 크기, 색, 부속지 유무), 미세 형태학적 형질(표면무늬, 종피세포 형태)을 자세히 관찰 하고 기재하였다. 본 분류군에서는 종자의 외형, 크기, 표 면무늬 형질에서 다양성을 관찰하였고, 분류학적 식별을 위한 형질의 유용성을 확인하였다.

종자의 외형은 원형 $(\mathrm{C})$, 쉼표형 $(\mathrm{Co})$, 타원형(E), 난형(O), 양배형 $(\mathrm{P})$, 신장형 $(\mathrm{R})$, 아원형 $(\mathrm{SC})$ 으로 다양하게 나타났으 며, 연구된 분류군 중 점나도나물속(Cerastium)과 개미자 리속(Sagina) 내 분류군이 각각 양배형 $(\mathrm{P})$ 과 타원형(E)으 로 일관성 있게 나타났고, 나머지 분류군에서는 동일 속 내에서도 다양한 종자 유형이 확인되었다. Sadeghian et al. (2014)은 벼룩이자리속(Arenaria)과 근연속의 종자형태연 구에서 종자의 외형이 속간 한계 설정을 위한 형질로는 유용하지 않지만 일부 속을 인식하는 데에는 유용한 형질 이 될 수 있음을 언급한 바 있다. 본 연구 결과에서도 종자 의 외형만으로 족 내 속을 구별하기에는 무리가 있었지만, 연구된 다양한 유형의 종자 외형에 대한 정보가 향후 족 내 분류군 식별을 위한 1차적 접근으로 유용하게 사용될 수 있음을 확인하였다. 속 내에서 나타나는 종자 외형의 다양성은 일부 속 내 분류체계 설정을 위한 형질로 활용 되기도 하는데, Crow (1979)는 개미자리속(Sagina) 내 15 분류군의 종자 외형을 크게 삼각형과 신장형 혹은 구형으 로 각각 두 개의 유형("saginoid", "crassuloid type")으로 구 별하였고, 본 형질을 기반으로 두 개의 절(sect. Sagina, sect. Maxima)로 구분하여 인식하였다. 따라서, 향후 속 내 다양 한 종자 외형을 지니는 분류군의 경우 외부형태학적 형질 뿐만 아니라 종자의 외형을 통해서도 속 내 분류체계를 재정립할 수 있는지 탐색할 필요가 있다.

연구된 한국산 Alsineae 종자의 크기는 평균 1.06 $\times 1.00 \mathrm{~mm}(\mathrm{~L} \times \mathrm{W})$ 로 나타났는데, 전체 평균과 비교하여 속 내 분류군의 평균이 크게 차이 나거나, 분류군 사이 크기의 중첩이 나타나지 않고 뚜렷하게 구별되는 경우를 확인할 있었다. 특히, 연구 분류군 중 갯별꽃(Honkenya peploides var. major)과 개미자리속(Sagina) 분류군 사이의 크기는 중첩 없이 쉽게 구별되었는데, 족 내에서 종자의 크기 형 질이 이들 두 속을 식별하는 주요 형질임을 확인하였다.

종자의 색은 갈색에서, 진갈색, 적갈색, 황갈색으로 다 양하게 나타났는데, 색만으로는 속이나 종을 구별하기에
는 유용한 형질로 적용하기 어려웠다. 또한 Sadeghian et al. (2014)에 따르면 일부 확연히 구별되는 분류군을 제외하 고는, 일반적으로 성숙된 종자의 색이 분류군을 동정하는 데 유용하지 않음을 제시한 바 있다. 본 연구 분류군에서 는 색과 광택 유무의 조합으로 분류군을 기재하였는데, 광택에 있어서는 갯별꽃(H. peploides var. major)의 가장 강 하게 나타나 족 내 다른 분류군과 구별할 수 있었다.

종자의 부속지(appendage)는 다양한 형태로 나타나며 이는 종자의 분산과 연관되는 것으로 알려져 있다(Singh and Mathur, 2004). 하지만, 부속지가 aril, rim aril, arilloid, caruncle, strophiole, crest, elaiosome 등 연구자에 따라 다양 한 용어로 언급되고 있어, 용어선택에 혼란을 주고 있다 (Grear and Dengler, 1976). 부속지를 나타내는 용어는 발생 과정 상 유래 기관에 따라 구별되며 이를 통한 정확한 용 어 선정이 요구되는데, strophiole의 경우, 주병(funiculus)에 서 유래하여 발생한 기관으로 정의하거나(Fahn and Werker, 1972; Hind, 1988; Minuto et al., 2006), 혹은 제조 (raphe)에서 발생한 것으로 정의하고 있다(Kapil et al., 1980). 최근 콩과 aril의 개체발생학(ontogeny)적 연구와 개 정된 Kew의 식물 용어집에서는 aril을 주병에서 발생한 것 으로 정의하고, strophiole을 제조에서 발생한 것으로 구별 하고 있어(Rodrìguez et al., 2006; Beentje, 2010), 이 또한 용 어 선택에 혼란이 있다. 본 연구에서는 Minuto et al. (2006) 이 개벼룩속(Moehringia) 종자의 연구 결과에서 제시한 strophiole을 사용하여 기재 하였으나, 본 분류군의 개체발 생학적 연구와 용어 정리를 통해 가종피로 불리는 기관에 대한 보다 심도 있는 연구가 필요한 것으로 판단하였다.

Hind (1988)는 개벼룩속(Moehringia) 종자의 strophiole을 미세형태에 따라 크게 5가지 유형으로 구별하였다("true amorphous, umbraculiform, hyphal, papillate, papillatecomplex"). 특히, Minuto et al. (2006)은 본 속 내에서 strophiole형질이 분류학적으로 매우 유용한 형질이며, 이 들의 유형이 분류군의 서식지와 밀접하게 연관되어 있음 을 제시하였다. 특히, 속 내 가장 일반적으로 나타나는 두 유형 중 "hyphal type"은 제한적으로 바위나 절벽에 서식하 는 고산식물에서 나타나며, "umbraculiform type"은 일반적 으로 넓게 분포하여 서식하는 분류군에서 나타난다고 주 장하였다(Minuto et al., 2006). 국내에는 속 내 개벼룩 (Moehringia lateriflora) 한 종이 숲가나 길가에 넓게 퍼져 서식하는 것으로 알려져 있고(Hong and Choi, 2007), 본 연 구 결과, Minuto et al. (2006)이 제시한 "umbraculiform type" 의 strophiole의 형태를 지니고 있는 바, strophiole 형태와 서 식지 간 상관성을 제시한 주장을 지지하였다. 또한, 한국산 Alsineae 전체 분류군 중에서도 개벼룩속(Moehringia) 종자 에서만 strophiole이 나타나, 분류학적으로도 매우 유용한 형질임을 확인하였다. 최근에는 개벼룩속(Moehringia) 종 자의 strophiole 크기, 형태 및 화학적 조성과 분산과의 연 관성에 대한 연구에서 개미산포분산(myrmecochory)의 확 
인과 함께 이들 기작에 대한 이점을 제시한 바 있다 (Casazza et al., 2008). 특히, 개벼룩(Moehringia lateriflora)에 대해서는 담수를 통해 분산이 된다는 주장이 있는데 (Julin, 1957), 국내 분포 및 서식지를 고려해 보았을 때 일 리 있는 주장으로 받아들여지기 어렵다. 따라서, 개벼룩 (Moehringia lateriflora)에 대한 보다 면밀한 서식지 분포와 분산기작에 대한 연구를 통해 종자 내 strophiole 구조와 기 능에 대해 정확히 밝힐 필요가 있다.

개벼룩속(Moehringia) 종자는 근연분류군인 벼룩이자리 속(Arenaria)과 비교하여 제 부위에 부속지(hilar appendage) 가 있는 특징으로 구별되며(Hind, 1988; Dequan et al., 2001; Rabeler and Hartman, 2005), 본 연구에서도 개벼룩속 (Moehringia)에서만 부속지와 strophiole가 함께 확인되어 구별되었다. 또한, 점나도나물속(Cerastium)에는 나선형의 부속지가 관찰되었고, 갯별꽃속(Honkenya)에서는 곤봉형, 개벼룩속(Moehringia)에서도 strophiole 안쪽에 곤봉형의 부 속지가 확인되었다. 특히, 점나도나물속(Cerastium)의 나 선형 부속지는 이전의 다른 연구에서는 확인되지 않았는 데(Yildiz, 2002; Minuto et al., 2006; Kanwal et al., 2012; Sadeghian et al., 2014), 속 내 보다 확장된 분류군을 통해 이 들 구조와 기능에 대해 연구 할 필요가 있다.

최근까지 수행된 많은 연구에서 석죽과 종자의 종자표 면무늬가 과 내 다양한 분류군의 분류학적 한계설정과 계 통학적 유용성을 나타낸다고 보고된 바 있다(Wyatt, 1984; Yildiz and Cirpici, 1998; Hong et al., 1999; Abuhadra, 2000; Yildiz, 2002; Minuto et al., 2006; Amini et al., 2011; Kanwal et al., 2012; Mahdavi et al., 2012; Mostafavi et al., 2013; Sadeghian et al., 2014). 본 연구에서도 표면무늬에 따라 크 게 4 가지 유형으로 구분하였는데 특히, 개미자리속 (Sagina)은 구릉상-유두형(Col-Pap)으로 족 내 다른 분류군 과 확연히 구별되었고, 개벼룩속(Moehringia)과 갯별꽃속 (Honkenya)은 평활상 $(\mathrm{Sm})$ 으로 분명하게 구별되었다. 또한, 종피세포의 수층벽, 병층벽 형태에 따라 보다 세부적으로 구분할 수 있었다. 삼수개미자리(Minuartia verna var. coreana)와 차일봉개미자리(M. macrocarpa var. koreana)의 경우 화서, 꽃받침의 길이 및 형태 등의 형질로 두 분류군 이 구분되나(Dequan and McNeill, 2001; Hong and Choi, 2007), 삼수개미자리가 차일봉개미자리의 이명으로 처리 되는 경우도 있다(Chang et al., 2014). 본 종자형태학적 형 질로는 두 분류군이 각각 구릉상-기둥형 $(\mathrm{Col}-\mathrm{Cll})$, 구릉상단순형 (Col-Sim)으로 구별되어, 두 분류군을 구분하여 인 식하는 것이 바람직하다고 판단하였다.

본 족이 포함되는 Alsinoideae 내 분류체계는 다양하게 인 식되어 왔는데, McNeill (1962)의 체계에 따르면 다음의 3개 그룹 내에 연구분류군이 포함되며[벼룩이자리속(Arenaria) group: 벼룩이자리속(Arenaria), 갯별꽃속(Honkenya), 나도개 미자리속(Mimuartia), 개벼룩속(Moehringia); 별꽃속(Stellaria) -점나도나물속(Cerastium) group: 점나도나물속(Cerastium),
개별꽃속(Pseudostellaria), 별꽃속(Stellaria); 개미자리속 (Sagina) group: 개미자리속(Sagina)], 최근의 분자계통학적 연구에 따르면, 본 족에 포함되는 8 개 속이 각각 5 개의 족 (Alsineae, Arenarieae, Sagineae, Sclerantheae, Sperguleae) 내 에 나뉘어 위치하는 것으로 나타났다(Harbaugh et al., 2010). 본 연구 결과, 병층세포벽이 볼록하고, 유두상 세포 가 나타나는 구릉상-유두형(Col-Pap)이 개미자리속(Sagina) 에서만 관찰되었는데, 족 내 본 속을 독립적인 개미자리 속(Sagina) group으로 인식한 McNeill (1962)과는 달리 분 자계통학적 결과에서는 Sagineae에 개미자리속(Sagina)과 나도개미자리속(Minuartia) 일부 분류군을 포함시키고 있 다(Harbaugh et al., 2010). 또한, 평활상 $(\mathrm{Sm})$ 의 표면무늬가 갯별꽃속(Honkenya)과 개벼룩속(Moehringia) 두 속에서만 나타났는데, McNeill (1962)은 두 속을 포함한 벼룩이자리 속(Arenaria) group으로 인식한 반면, Harbaugh et al. (2010) 의 분자계통학적 체계에서는 Sclerantheae에 갯별꽃속 (Honkenya), Arenarieae에 개벼룩속(Moehringia)으로 따로 위치하여 인식하고 있다. 비록 Alsineae (sensu Bittrich, 1993)에 속하는 총 23 개 속 중 국내에 분포하는 8 개 속에 국한된 연구 결과이지만, 본 종자 표면무늬 패턴의 연구 결과는 McNeill (1962)의 체계를 지지하였다. 추후, Alsineae 에 해당하는 모든 분류군으로의 확장 및 Harbaugh et al. (2010), Greenberg and Donoghue (2011)의 최근 분자계통학 적 연구결과에서 확인된 Alsineae과 연관된 분류군을 포 함하여, 종자형태의 계통학적 해석 및 진화적 경향성을 파악해야 할 것이다.

결론적으로, 한국산 Alsineae 종자의 외형, 크기, 부속지, 표면무늬, 종피세포 형태 등의 형질이 분류학적으로 유용 한 형질임을 밝혔고, 유일하게 개벼룩속(Moehringia)에서 만 관찰되는 strophiole의 분류학적 유용성을 확인하였으 며, 정확한 정의와 발생학적, 생태학적 연구의 필요성을 제안하였다. 종자의 표면무늬를 통해 McNeill (1962)의 Alsinoideae 내 분류체계를 지지하나, 추후 족 내 혹은 아과 내 모든 분류군으로의 확장과 더불어 최근 분자계통학적 결과와의 비교를 통해 종자형태의 계통학적, 진화학적 해 석이 필요한 것으로 판단하였다.

\section{사 사}

본 연구를 위해 표본을 대여해주신 $\mathrm{KH}, \mathrm{KHUS}, \mathrm{S}, \mathrm{SKK}$, SUNA, UPS의 관계자분들께 감사를 드립니다. 또한 심사 과정 중 보다 정확한 논문이 되도록 교정을 해주신 익명 의 두 분 심사자들께 감사드립니다. 끝으로 본 연구과정에 도움을 아끼지 않은 경희대학교 생물학과 식물계통분류 학 연구실의 동료들께 고마운 마음을 전합니다. 본 연구는 한국연구재단 기본연구비(NRF-2012R1A1A2004149)의 일 부 지원과 국립수목원 용역과제(No. 20150437)의 일부게 재료 지원으로 수행되었습니다. 


\section{Literature Cited}

Abuhadra, M. N. 2000. Taxonomic studies on the Arenaria serpyllifolia group (Caryophyllaceae). Flora Mediterranea 10: 185190.

Amini, E., S. Zarre and M. Assadi. 2011. Seed micromorphology and its systematic significance in Gypsophila (Caryophyllaceae) and allied genera. Nordic Journal of Botany 29: 660669.

Barthlott, W. 1981. Epidermal and seed surface characters of plants: systematic applicability and some evolutionary aspects. Nordic Journal of Botany 1: 345-355.

Barthlott, W. 1984. Microstructural features of seed surface. In Current Concepts in Plant Taxonomy. Heywood, V. H. and D. M. Moore (eds.), Academic Press, London. Pp. 95-105.

Beentje, H. J. 2010. The Kew Plant Glossary: an illustrated dictionary of plant terms. Royal Botanic Gardens, Kew, Richmond.

Bittrich, V. 1993. Caryophyllaceae. In The Families and Genera of Vascular Plants, Vol. 2. Kubitzki, K., V. Bittrich and J. Rohwer (eds.), Springer, Berlin. Pp. 206-230.

Casazza, G., B. Borghesi, E. Roccotiello and L. Minuto. 2008. Dispersal mechanisms in some representatives of the genus Moehringia L. (Caryophyllaceae). Acta Oecologica 33: 246-252.

Chang, C. S., H. Kim and K. S. Chang. 2014. Provisional Checklist of Vascular Plants for the Korea Peninsula Flora (KPF). Designpost, Seoul.

Chrtek, J. and Z. Slavikova. 1987. Leitbündelanordnung in den Kronblättern von ausgewählten Arten der Familie Stellariaceae. Preslia 60: 11-21.

Crow, G. E. 1979. The systematic significance of seed morphology in Sagina (Caryophyllaceae) under scanning electron microscopy. Brittonia 31: 52-63.

Dequan, L. and J. McNeill. 2001. Minuartia. In Flora of China, Vol. 6. Wu, Z. Y., P. H. Raven and D. Y. Hong (eds.), Science Press and Missouri Botanical Garden Press, Beijing and St. Louis. Pp. 29-31.

Dequan, L., W. Zhengyi, Z. Lihua, C. Shilong, M. G. Gilbert, M. Liden, J. McNeill, J. K. Morton, B. Oxelman, R. K. Rabeler, M. Thulin, N. J. Turland and W. L. Wagner. 2001. Caryophyllaceae. In Flora of China, Vol. 6. Wu, Z. Y., P. H. Raven and D. Y. Hong (eds.), Science Press and Missouri Botanical Garden Press, Beijing and St. Louis. Pp. 1-133.

Fahn, A. and E. Werker. 1972. Anatomical mechanisms of seed dispersal. In Seed Biology, Vol. 1. Kozlowski, T. T. (ed.), Academic Press, New York. Pp. 151-221.

Fior, S., P. O. Karis, G. Casazza, L. Minuto and F. Sala. 2006. Molecular phylogeny of the Caryophyllaceae (Caryophylla- les) inferred from chloroplast matK and nuclear rDNA ITS sequences. American Journal of Botany 93: 399-411.

Frajman, B., F. Eggens and B. Oxelman. 2009. Hybrid origins and homoploid reticulate evolution within Heliosperma (Sileneae, Caryophyllaceae): A multigene phylogenetic approach with relative dating. Systematic Biology 58: 328-345.

Grear, J. W. and N. G. Dengler. 1976. The seed appendage of Eriosema (Fabaceae). Brittonia 28: 281-288.

Greenberg, A. K. and M. J. Donoghue. 2011. Molecular systematics and character evolution in Caryophyllaceae. Taxon 60: 1637-1652.

Harbaugh, D. T., M. Nepokroeff, R. K. Rabeler, J. McNeill, E. A. Zimmer and W. L. Wagner. 2010. A new lineage-based tribal classification of the family Caryophyllaceae. International Journal of Plant Sciences 171: 185-198.

Heywood, V. H. 1969. Scanning Electron Microscopy in the study of plant material. Micron 1: 1-14.

Hind, D. J. N. 1988. The biology and systematics of Moehringia L. (Caryophyllaceae). Ph.D. Thesis. University of Reading, Reading.

Hong, S. P., M. J. Han and K. J. Kim. 1999. Systematic significance of seed coat morphology in Silene L. s. str. (SilenenaeCaryophyllaceae) from Korea. Journal of Plant Biology 42: 146-150.

Hong, S. P. and K. Choi. 2007. Caryophyllaceae. In The Genera of Vascular Plants of Korea. Park, C.-W. (ed.), Academy Publishing Co., Seoul. Pp. 310-333.

Julin, E. 1957. De Svenska localerma for Moehringia lateriflora (L.) Fenzl. Botaniska Notiser 100: 307-312.

Kanwal, D., R. Abid and M. Qaiser. 2012. The seed atlas of Pakistan-VI. Caryophyllaceae. Pakistan Journal of Botany 44: 407-424.

Kapil, R. N., J. Bor and F. Bouman. 1980. Seed appendages in Angiosperms. I. Introduction. Botanische Jahrbücher für Systematik 101: 555-573.

Mahdavi, M., M. Assadi, F. Fallahian and T. Nejadsattari. 2012. The systematic significance of seed micromorphology in Stellaria L. (Caryophyllaceae) and its closest relatives in Iran. The Iranian Journal of Botany 18: 302-310.

McNeill, J. 1962. Taxonomic studies in the Alsinoideae I. Generic and infra-generic groups. Notes from the Royal Botanic Garden, Edinburgh 24: 79-155.

Minuto, L., S. Fior, E. Roccotiello and G. Casazza. 2006. Seed morphology in Moehringia L. and its taxonomic significance in comparative studies within the Caryophyllaceae. Plant Systematics and Evolution 262: 189-208.

Mostafavi, G., M. Assadi, T. Nejadsattari, F. Sharifnia and I. Mehregan. 2013. Seed micromorphological survey of the Min- 
uartia species (Caryophyllaceae) in Iran. Turkish Journal of Botany 37: 446-454.

Murley, M. R. 1951. Seeds of the Cruciferae of North Eastern America. The American Midland Naturalist 46: 1-81.

Pax, F. and K. Hoffmann. 1934. Caryophyllaceae. In Die natürlichen Pflanzenfamilien, $2^{\text {nd }}$ ed. Engler, A. and K. Prantl (eds.), Engelmann, Leipzig. Pp. 275-364.

Rabeler, R. K. and R. L. Hartman. 2005. Caryophyllaceae. In Flora of North America, Vol. 5. Flora of North America Editorial Committee (eds.), Oxford University Press, New York. Pp. 3-8.

Rodríguez-Riaño, T., F. J. Valtueña and A. Ortega-Olivencia. 2006. Megasporogenesis, megagametogenesis and ontogeny of the aril in Cytisus striatus and C. multiflorus (Leguminosae: Papilionoideae). Annals of Botany 98: 777-791.

Sadeghian, S., S. Zarre and G. Heubl. 2014. Systematic implication of seed micromorphology in Arenaria (Caryophyllaceae) and allied genera. Flora 209: 513-529.

Singh, D. and S. B. Mathur. 2004. Histopathology of seed-borne infections. CRC Press, Florida. Pp. 47-80.

Smissen, R.D., P. J. Garnock-Jones and G. K. Chambers. 2003. Phylogenetic analysis of ITS sequences suggests a Pliocene origin for the bipolar distribution of Scleranthus (Caryophyllaceae). Australian Systematic Botany 16: 301-315.

Thiers, B. 2015. (Continuously updated) Index Herbariorum: a global directory of public herbaria and associated staff. New York Botanical Garden's Virtual Herbarium. Available at: http://sweetgum.nybg.org/ih/

Wyatt, R. 1984. Intraspecific variation in seed morphology of Arenaria uniflora (Caryophyllaceae). Systematic Botany 9: 423431.

Yildiz, K. 2002. Seed morphology of Caryophyllaceae species from Turkey (North Anatolia). Pakistan Journal of Botany 34: 161-171.

Yildiz, K. and A. Cirpici. 1998. Seed morphological studies of Silene L., from Turkey. Pakistan Journal of Botany 30: 173188. 


\section{Appendix. Specimens examined.}

Arenaria juncea: Mongolia, without precise locality, Aug. 1919, Eriksson 959 (S).

Arenaria serpyllifolia: Korea, Seoul, Seoul National University, without date, Lee 13254 (SUNA); Gyeonggi-do, Mt. Gwanggyosan, Apr. 1967, Han 13249 (SUNA).

Cerastium fischerianum: Korea, Gyeonggi-do, Mt. Cheonggye-san, May 1992, Lee 13265 (SUNA); Gyeongsangbuk-do, Mungyeong-sae-jae, Jun. 1991, Lee 13270 (SUNA).

Cerastium glomeratum: Korea, Jeollabuk-do, Mt. Palgong-san, Jun. 2005, Ryu 80341 (SUNA).

Cerastium holosteoides var. hallaisanense: Korea, Gyeonggi-do, Mt. Cheonggye-san, without date, Lee 13311 (SNUA); Jeollanam-do, Mt. Jiri-san, Jul. 1982, Lee 13321 (SNUA); Gyeongsangnam-do, Mt. Jiri-san, May 2004, Lim 78427 (SNUA).

Cerastium pauciflorum: Korea, Gyeonggi-do, Mt. Myeongji-san, May 1996, Chang 13362 (SUNA).

Cerastium rubescens var. koreanum: Korea, Gangwon-do, Mt. Daeam-san, Jul. 2000, Chang et al. 41996 (SUNA).

Honkenya peploides var. major: Sweden, without precise locality, Aug. 1957, H. Nannfeldt 15007 (UPS); Without precise locality and date, Dusén s.n. (UPS).

Minuartia arctica: Without precise locality and date, T. Heyaeba s.n. (UPS).

Minuartia macrocarpa var. koreana: Russia, Siberia, without date, E. Hultén 2476 (S).

Minuartia verna var. coreana: Without precise localitis and dates, H. Neumayer s.n. (UPS); Thuliu 1892 (S).

Moehringia lateriflora: Korea, Gangwon-do, Gun-ja, Jun. 1965, Lee et al. 13783 (SNUA); Gyeonggi-do, Suwon, Jun. 1980, Lee s.n. (SNUA); Suwon, Apr. 1967, Lee 13752 (SNUA).

Pseudostellaria davidii: Korea, Gangwon-do, Mt. Seorak-san, May 1996, Cho 13803 (SNUA).

Pseudostellaria heterophylla: Korea, Seoul, Seoul National University, May 1971, Lee 13861 (SNUA); Jeollabuk-do, Janggugun, Mt. Palgong-san, Apr. 2005, Chang 81156 (SNUA); Gwangseung-ri, May 1960, Han 13858 (SNUA).

Pseudostellaria okamotoi: Korea, Jeollanam-do, Mt. Jiri-san, Jun. 1984, Lee 13893 (SNUA); Lee 13895 (SNUA).

Pseudostellaria palibiniana: Korea, Jeollabuk-do, Gwangseung-ri, Jun. 1960, Gwak 13913 (SNUA); Chungcheongnam-do, Mt. Cheontae-san, Jun. 2006, Nam and Koh 60199 (KH).

Pseudostellaria sylvatica: North Korea, Mt. Baekdu-san, Jul. 2004, Ahn s.n. (KH).

Sagina japonica: Korea, Incheon, Mt. Munhak-san, Jun. 1996, Park and Kim 13943 (SNUA); Jeollanam-do, Mt. Jiri-san, Jun. 1971, Lee 13958 (SUNA); Jeju-do, without precise locality, Jun. 1992, Mun 60566 (SKK).

Sagina maxima: Korea, Gangwon-do, Mt. Nak-san, May 1966, Lee 13964 (SNUA); Gun-ja, Jun. 1965, Lee et al. 14065 (SNUA).

Stellaria alsine var. undulata: Korea, Gyeonggi-do, Mt. Gwanggyo-san, Apr. 1981, Kim 14094 (SNUA); Incheon, Ongjin-gun, Deokjeok-do, Jul. 1976, Jang 8767 (SKK).

Stellaria aquatica: Korea, Gyeonggi-do, Suwon, Oct. 1959, Lee 14074 (SNUA); Suwon, Aug. 2000, Han 70345 (KHUS); Gyeongsangbuk-do, Mt. Chilbo-san, May 1996, Lee et al. 70343 (SNUA).

Stellaria filicaulis: Korea, Gyeonggi-do, Mt. Cheonma-san, Apr. 1994, Yu 65439 (SKK).

Stellaria longifolia: Korea, Gyeonggi-do, Yangpyeong-gun, Mt. Chueup-san, May 2003, Lim 70553 (SNUA); Suwon, Jun. 1966, Kang and Lee 14190 (SNUA); Gangwon-do, Wonju-si, Mt. Chiak-san, May 1995, Kim 25377 (SKK).

Stellaria media: Gyeonggi-do, Gunpo, Jun. 1995, Ahn 25388 (SKK); Gangwon-do, Pyeongchang-gun, Jul. 2001, Chang 50996 (SNUA); Gyeongsangbuk-do, Mt. Undal-san, Apr. 2000, Chin 41321 (SNUA).

Stellaria radians: China, Jilin province, Hwaryong-si, Dumangang River, Jul. 2004, Jeon 41558 (KH). 